\title{
Le diagnostic archéologique des combles de l'abbaye de Reigny à Vermenton (Yonne)
}

\section{Sylvain Aumard}

\section{(2) OpenEdition}

1 Journals

\section{Édition électronique}

URL : https://journals.openedition.org/cem/11312

DOI : $10.4000 /$ cem. 11312

ISSN : 1954-3093

\section{Éditeur}

Centre d'études médiévales Saint-Germain d'Auxerre

\section{Édition imprimée}

Date de publication : 15 août 2009

Pagination : 99-101

ISSN : 1623-5770

\section{Référence électronique}

Sylvain Aumard, « Le diagnostic archéologique des combles de l'abbaye de Reigny à Vermenton

(Yonne) ", Bulletin du centre d'études médiévales d'Auxerre | BUCEMA [En ligne], 13 | 2009, mis en ligne le 16 septembre 2009, consulté le 22 septembre 2022. URL : http://journals.openedition.org/cem/11312 ; DOI : https://doi.org/10.4000/cem.11312

Ce document a été généré automatiquement le 22 septembre 2022.

\section{(c)}

Creative Commons - Attribution - Pas d'Utilisation Commerciale - Partage dans les Mêmes Conditions 4.0 International - CC BY-NC-SA 4.0

https://creativecommons.org/licenses/by-nc-sa/4.0/ 


\title{
Le diagnostic archéologique des combles de l'abbaye de Reigny à Vermenton (Yonne)
}

\author{
Sylvain Aumard
}

1 En prévision de futurs travaux de restauration des combles, l'Association des amis de l'abbaye de Reigny, a donné une suite favorable à la proposition de diagnostic archéologique proposée par le CEM. L'originalité de cette démarche est le fruit d'une réflexion constatant l'absence d'outil de prospectivescientifique dans le domaine des monuments historiques à l'égal de ceux qui existent déjà dans les autres filières patrimoniales - carte archéologique des DRAC par exemple... Ce document ne constitue pas l'étude complète des combles, mais seulement un état des lieux permettant, d'abord, d'évaluer leur potentiel historique et, ensuite, d'orienter de telles études en fonction de l'impact des travaux de restauration.

2 De l'ensemble monastique cistercien, il ne reste plus aujourd'hui que le carré méridional formé par le bâtiment des moines à l'est - prolongement de l'aile orientale du cloître - et le réfectoire à l'ouest, le tout relié par les ailes nord et sud. Seul le réfectoire a conservé sa charpente d'origine (XIV ${ }^{\mathrm{e}}$ siècle ?), dont la conception originale participe de la justification d'une datation dendrochronologique - faible pente, pannes soutenues par des tridents, similitude avec la charpente du chœur de l'église de Vermenton. De nombreux étaiements anciens ont été fabriqués à l'aide de remplois, parmi lesquels on discerne des éléments ayant appartenu à une charpente des XII ${ }^{\mathrm{e}}$ $\mathrm{XIII}^{\mathrm{e}}$ siècle (assemblages à mi-bois) de provenance inconnue (abbatiale ? aile nord ?). Le bâtiment des moines, bien que de réalisation ancienne (XIII ${ }^{\mathrm{e}}$ siècle ?), possède une charpente plus tardive, peut-être du XVI ${ }^{\mathrm{e}}$ siècle. L'étude poussée de son pignon sud permettrait probablement de mieux deviner la structure disparue du XIII ${ }^{\mathrm{e}}$ siècle en s'attardant sur les enduits et l'intégration de ses grandes baies dans les volumes d'origine. 
3 Au cours des $\mathrm{XVIII}^{\mathrm{e}}$-XIX ${ }^{\mathrm{e}}$ siècles, les ailes nord et sud ont subi de très importantes modifications de leurs dispositions, qui, vraisemblablement, étaient jusqu'alors restés dans leur état du XII ${ }^{\mathrm{e}}$ siècle. L'aile nord, constituée d'un seul niveau de plain-pied (voûté ?), aurait été rehaussée d'un étage tandis que l'aile sud aurait vu un remplacement complet de sa galerie de circulation médiévale et un exhaussement de son toit dont la couverture reposait directement sur la voûte. L'étude de ces maçonneries permettrait non seulement de vérifier et de préciser ces hypothèses, mais également d'appréhender les plus anciennes architectures conservées sur le site.

De nombreux matériaux de couverture médiévaux ont été retrouvés aussi bien en remplois dans bon nombre des couvertures actuelles qu'en débris ou gravats sur les reins de voûte du réfectoire. Leur richesse et leur diversité sont à même de participer à la connaissance des matériaux de couverture médiévaux, notamment pour les tuiles creuses à crochet, qui témoignent d'une technique encore totalement méconnue dans nos régions.

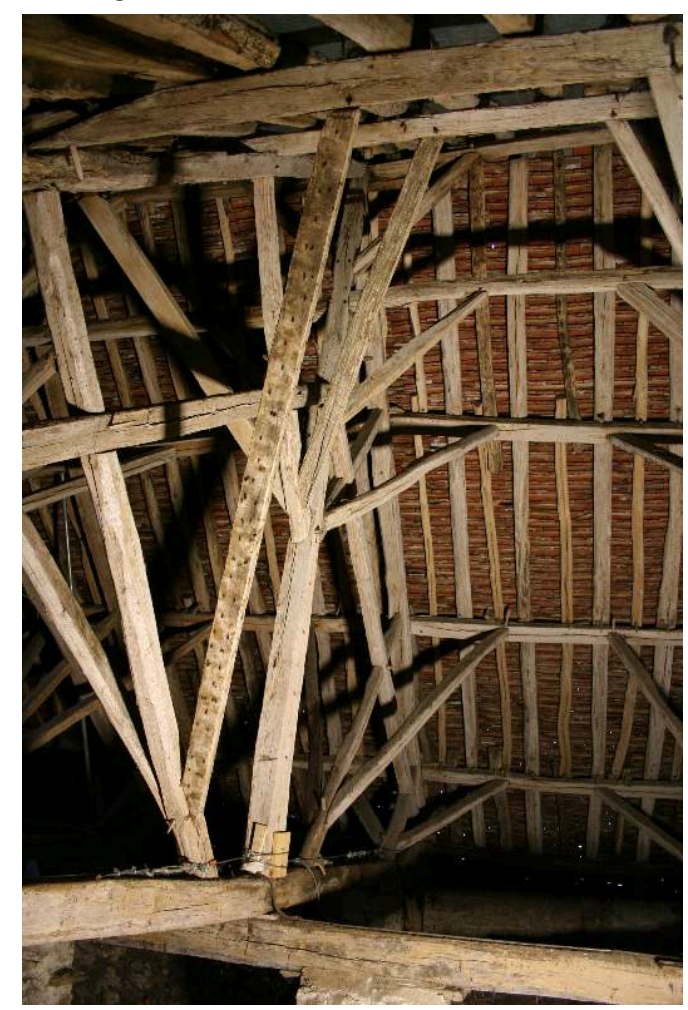

Fig. 1 - Vermenton, abbaye de Reigny : charpente du réfectoire, ferme avec multiples contrefiches à trident (cl. S. Aumard). 
INDEX

Mots-clés : abbaye, combles

Index géographique : France/Reigny 